\title{
Design and manufacturing of abrasive jet machine for drilling operation
}

\author{
Divyansh Mittal $^{1 \mathrm{a}}$, Shankar Sehgal ${ }^{1}$ and Harmesh Kumar $^{1}$ \\ Mechanical Engineering Department, UIET, Panjab University, Chandigarh
}

\begin{abstract}
Wide application of Abrasive Jet Machine (AJM) is found in machining hard and brittle materials. Machining of brittle materials by AJM is due to brittle fracture and removal of micro chips from the work piece. Embedment of the abrasive particles in the brittle materials results in decrease of machining efficiency. In this paper design and manufacturing of AJM has been presented. Various parts of AJM have been designed using ANSYS 16.2 software. The parts are then manufactured indigenously as per designed parameters. The machine fabricated in this work will be used further for process optimization of AJM parameters for machining of glass and ceramics.
\end{abstract}

\section{Introduction}

Abrasive jet machining (AJM) is one of the most popular machining and surface finishing method among other non-conventional machining methods for drilling, cleaning, deburring, etching etc. of hard and brittle materials without vibrations, heat and stress. As the workpiece do not heat, therefore it does not experience any surface hardening.

In AJM, mixture of abrasive particles (typically $\sim 0.025$ $\mathrm{mm}$ ) and carrier gas is impinged on work piece through a nozzle of diameter 0.2 to $0.8 \mathrm{~mm}$ under controlled conditions. Aluminium oxides, silicon carbides, boron carbides, crushed glass, sodium bicarbonate, dolomite are various abrasive particles used in AJM.

In AJM, the pressurized gas is mixed with abrasive particles. This mixture is then passed through the nozzle, thereby converting pressure energy to kinetic energy. High velocity jet is then impinged on workpiece which converts the kinetic energy of the jet to mechanical energy and thus the material is removed by micro cutting action and brittle fracture. In AJM, material removal results in the development of a number of small craters on the surface of the workpiece being machined.

In $\mathrm{AJM}$, the cutting forces acting on the workpiece, which are responsible for machining, are directed downward. Due to this, a material with very small thickness can be machined. Nowadays AJM is being used for deburring external burs. Balasubramaniam et al.[1] deburred cross drilled holes by secondary mechanism and found that while deburring cross drilled holes with AJM, abrasive particles must be coarse. With investigation and advancement, AJM was used in machining hard and brittle materials like glass and ceramics.

\footnotetext{
${ }^{1 a}$ Corresponding author: divyanshmittal144@gmail.com
}

AJM had been considered most appropriate technology for machining hard and brittle materials and producing micro parts of semiconductors and LCD's. Microabrasive jet machining (MAJM) used finer abrasive particles and small diameter nozzle to produce smaller holes and more surface finish. Wensink and Elwenspoek [2] mentioned that when AJM is performed, inclination of sidewalls and blast lag (wide channels become deeper compared to smaller channels) were the reasons to limit the maximum aspect ratio. It was investigated that much steeper sidewalls and very less blast lag could be produced with use of MAJM. Kuriyagawa and Yoshida [3] worked on mechanism of MAJM. Park et al.[4] micro-grooved the glass with MAJM and found that accurate square type grooves cannot be formed with MAJM, as grooves formed were of U-type shape. Also due to the "blast lag effect" the dimensions of machined surface were slightly larger than masking patterns.

While machining, the abrasive particles may embed in the workpiece. These embedded particles will form a shield for next impinging abrasive particles. Due to this MRR would decrease significantly. As the particle embedding can be undesirable in numerous of applications, Getu el al. [5] identified two criteria for particle embedment in erosion process. Firstly, if the contiguous contact between the particle and the target was maintained throughout the impact, embedment was possible. Second was that the magnitude of the static friction forces must reach a critical value for embedment. Particle orientation was defined as the angle between the particle linear velocity vector and the line connecting the centre of mass to the furthest downstream particle vertex. It was observed that certain particle orientation were more favourable to particle embedment.

Hadavi et al.[6]worked on finding the process parameters which are dependent on particle orientation. A model 
capable of predicting the instantaneous particle orientation and velocity within and downstream of nozzle was presented and shown to agree well with measurements.

Zhang et al.[7] introduced the concept of micro abrasive intermittent jet machining (MAIJM) for producing small holes. MAIJM was a technology in which abrasive particles were mixed with carrier gas for some interval of time so that the embedded particles were blown out from the surface of material to be machined. MAIJM device was developed and empirical model was established with help of Taguchi orthogonal array and multi-variable linear regression. It was found that the model for MAIJM was highly adequate for producing small holes.

AJM is also combined with many other processes for hybrid machining. Different hybrid machining processes for more precise and accurate machining are abrasive electrical discharge machining, abrasive chemical discharge machining, abrasive discharge grinding and ultrasonic electrochemical machining [8].

In this paper design and fabrication of AJM is presented. Design of different units i.e. air distribution system, abrasive feeder chamber, mixing chamber and nozzle are made in AutoCAD software [9]. Material for the distributor, abrasive feeder and mixing chamber has been decided as mild steel as it has good formability and weldability. The chambers are fabricated as per the design with MIG welding. MIG welding is used because it results to a leak proof joint. Nozzle material is chosen as tungsten carbide due to its high wear resisting property. Note that boron carbide nozzle fabricated with powder metallurgy process can also be used. Fabrication is done such that the flow of abrasive particles in mixing chamber can be stopped manually with the help of a valve. A particular time can be set for which the abrasive particles are mixed with the carrier gas.

\section{Principle}

In AJM, nozzle angle play a great role in the mechanism of material removal. Nozzle angle can be $90^{\circ}$ or it can be oblique. For brittle material, material is removed in accordance with Theory of brittle failure. Therefore $90^{\circ}$ angle is kept for material removal in brittle materials. Fig 1 determines the principle i.e. brittle fracture in brittle materials. Due to brittle fracture very small particles are eroded from the surface of the workpiece.

Further the abrasive particles impinging with very high velocity are embedded in the workpiece as shown in fig 2. These embedded particles are responsible for the shielding from next impinging particles which lead to low machining efficiency. To augment the efficiency one need to remove these abrasive particles. This is done by distributing the compressed air in two sections so that the flow of abrasive particles may be closed. Further flow of air on the workpiece without mixing abrasive particles will remove the embedded particles. Fig 3 shows the removal of the embedded particles.

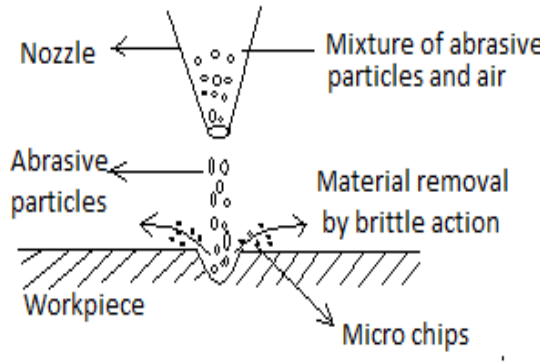

Figure 1. Micro cutting action of brittle material in AJM

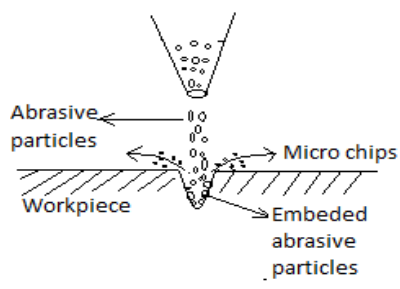

Figure 2. Embedment of abrasive particles in workpiece

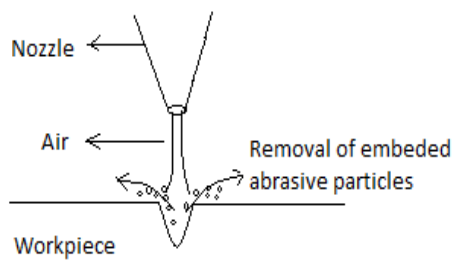

Figure 3. Removal of embedded abrasive particles

\section{Design methodology}

AJM is fabricated in the institute workshop with required raw materials and procured components. In house aircompressor and filter regulator (FR) unit have been used as accessories of the AJM. Before fabrication, design of each component is made. Different components designed are mixing chamber, abrasive feeder, nozzle, work holding device and glass chamber.

\subsection{Air compressor}

In air compressors, air is compressed to high pressure with the use of electric motor or internal combustion engine. In AJM high velocity jet is required to impinge on the work piece, which is obtained with highly pressured carrier gas compressed through air compressor. Air compressor will be used on 5 to 6 bar pressure. $5 \mathrm{~mm}$ thick sheet is used for the fabrication of distributor, abrasive feeder chamber and mixing chamber. Fig 4 shows the air compressor used for machining. 


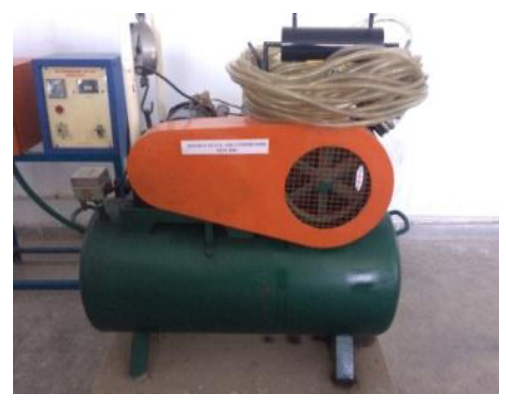

Figure 4. Air compressor

\subsection{FR unit}

FR unit is essential for filtering the air coming from compressor and regulating the pressure. FR unit removes the suspended dust particles, moisture and oil contents from the compressed air to prevent coagulation of particles and jam of nozzle opening. These filters have different types of membranes which are porous in nature and are of various sizes i.e. 5, 10, or $15 \mu \mathrm{ms}$. They restrict the particles bigger than the pores of membrane. After FR unit carrier gas is supplied to distributor.

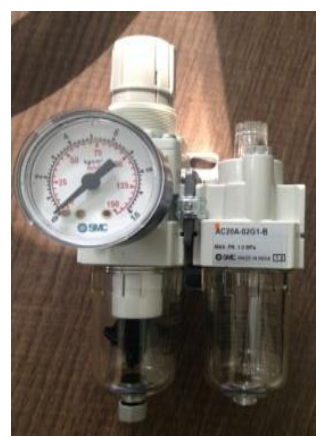

Figure 5. FR unit

\subsection{Air distributer}

Compressed air from air compressor after FR unit is passed to distributer. Pressure gauge is applied on distributer to measure the pressure of the carrier gas. Figure 6 provides the dimensions of distributor made in AutoCAD.
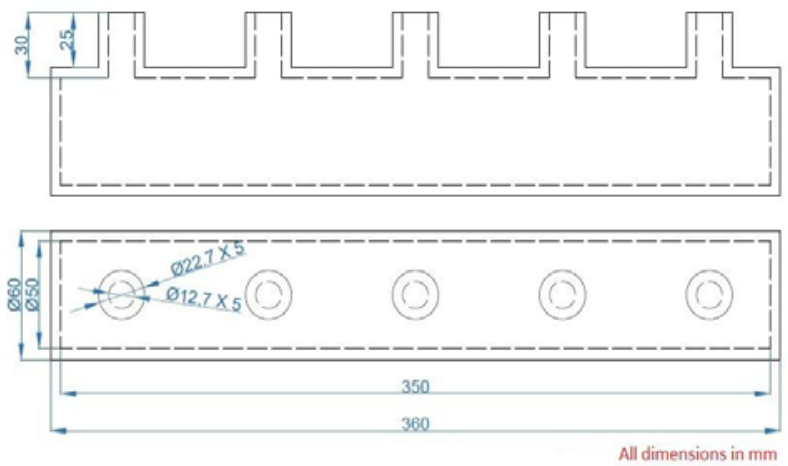

Material used for fabricating distributor is chosen as mild steel. Keeping thickness of the distributor $5 \mathrm{~mm}$, diameter $50 \mathrm{~mm}$ and welding efficiency $50 \%$ the factor of safety comes out to be 21 which is satisfactory. Figure 7 shows the fabricated distributor.

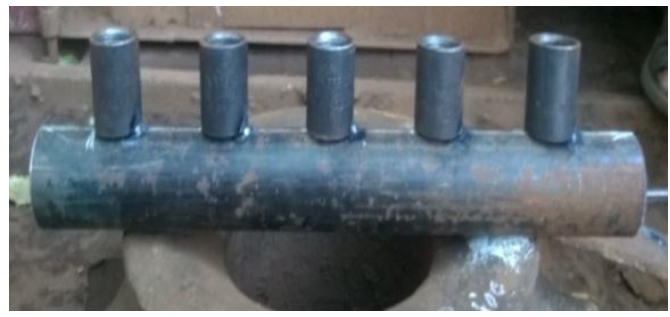

Figure 7. Air distribution system

\subsection{Abrasive feeder}

Abrasive chamber is fabricated with $5 \mathrm{~mm}$ thick sheet of mild steel. The diameter and height of the abrasive feeder chamber are kept $120 \mathrm{~mm}$. Drawing of abrasive feeder chamber is shown in figure 8 .
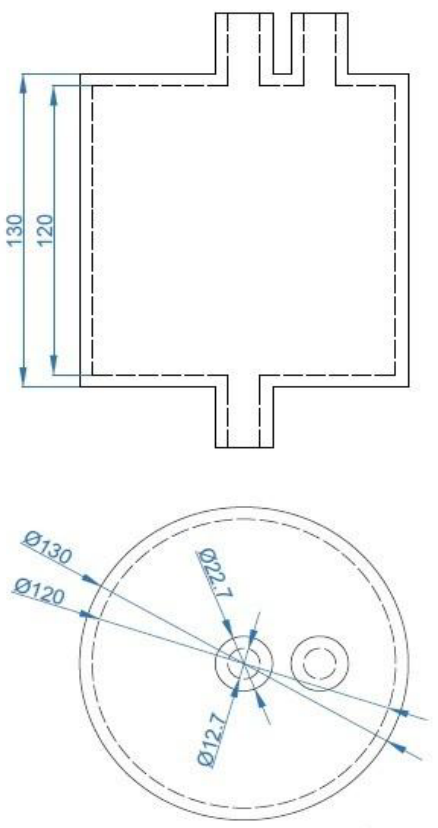

All dimensions in $\mathrm{mm}$

Figure 8. Front \& top view of abrasive feeder chamber

Abrasive particles like $\mathrm{Al}_{2} \mathrm{O}_{3}$ and $\mathrm{SiC}$ are used for machining the work piece. For good flowability of abrasive particles, carrier gas i.e. air will be mixed with abrasive particles in abrasive chamber. This mixing is for the better flow of abrasive particles which will further be mixed with air in mixing chamber. Abrasive particles are passed to the mixing chamber with ball valve opening. This valve is used for restricting the flow of abrasive particles in the mixing chamber when only air is needed for removing the embedded abrasive particles. Fabricated abrasive feeder chamber is shown in figure 9.

Figure 6. Front \& top view of air distributor system 


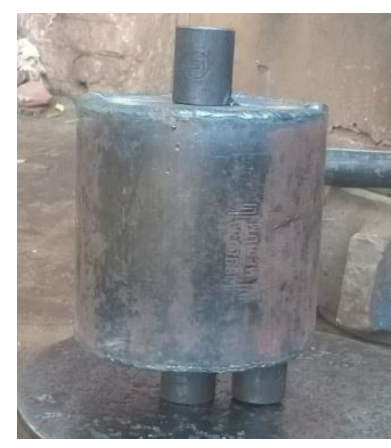

Figure 9. Abrasive feeder chamber

\subsection{Mixing chamber}

The fabrication of mixing chamber is done such that the carrier gas would enter from three different inlets at $120^{\circ}$ angle and abrasive particles would enter from the top of the mixing chamber. This would result in cyclone formation inside the mixing chamber and homogeneous mixture of abrasive particles and carrier gas will be obtained. Figure 10 shows design of mixing chamber.

The thickness of the mixing chamber is also kept $5 \mathrm{~mm}$. Figure 11 shows the fabricated mixing chamber. The converging section of the mixing chamber will ensure the increase in velocity of the mixture. Further increase in velocity is done in nozzle to achieve cutting velocity.

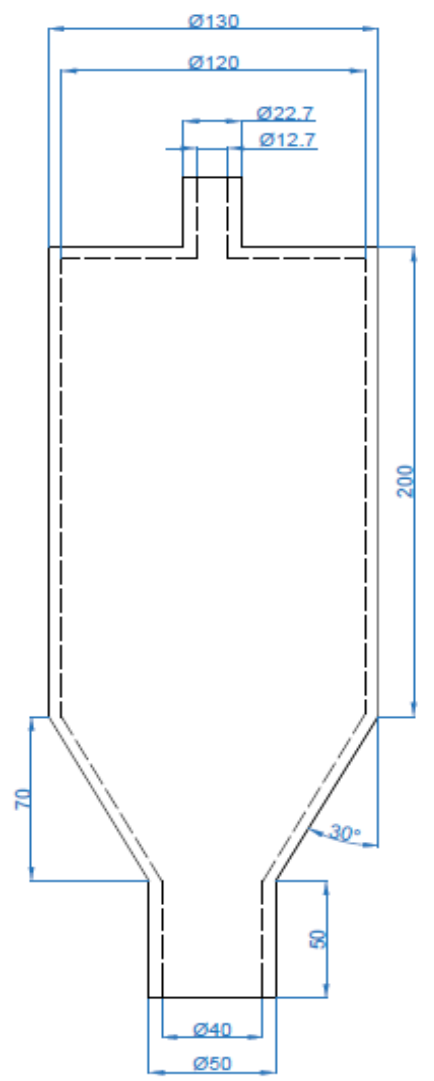

(a)

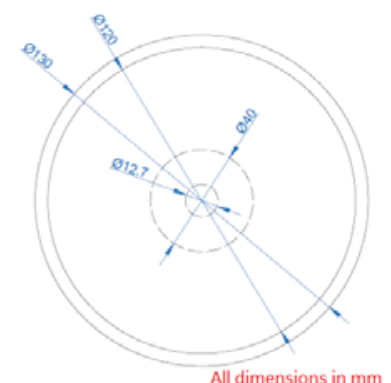

(b)

Figure. 10 (a) Front \& (b) top view of mixing chamber

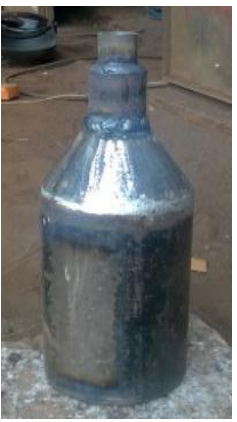

Figure 11. Mixing chamber

\subsection{Nozzle}

Nozzles are the devices which increases the kinetic energy of the fluid in exchange to the pressure drop. Nozzles create high velocity jet which is impinged on the material to be machined. As the nozzle wear is a big issue in AJM, tungsten carbide or sapphire material nozzle is used. Tungsten carbide nozzle can cut square, rectangular and circular section but sapphire nozzles can only cut circular sections. Average life of nozzle made of tungsten carbide is 12 to $20 \mathrm{hr}$ whereas nozzle made of sapphire has an average life of $300 \mathrm{hr}$. We will use tungsten carbide nozzle for the experimentation due to the ease of the availability and low cost in comparison to sapphire nozzle. SOD of $0.5 \mathrm{~mm}$ to $1.5 \mathrm{~mm}$ will be maintained. Design of nozzle is made in AutoCAD as shown in figure 12. Inlet and outlet diameter of nozzle is kept $8 \mathrm{~mm}$ and $0.8 \mathrm{~mm}$ respectively. Length of nozzle is $30 \mathrm{~mm}$. 

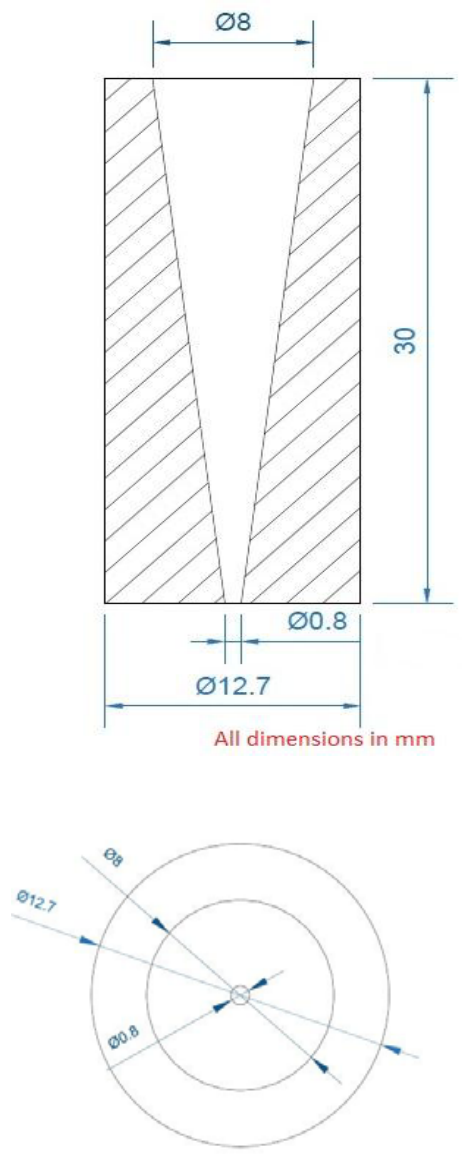

Figure 12 (a) Front \& (b) top view nozzle

Geometrical model created in AutoCAD was imported into the ANSYS as shown in figure 13. Meshing was done using auto mesh command. Mesh of inlet fluid was created as shown in figure 14. Inlet velocity was kept $10 \mathrm{~m} / \mathrm{s}$. Result was converged after 32 iterations and outlet velocity came out to be $1005.3 \mathrm{~m} / \mathrm{s}$. As per the theory, in AJM the outlet velocity of $300-700 \mathrm{~m} / \mathrm{s}$ is required. Considering losses this velocity can be achieved at nozzle outlet required for machining.

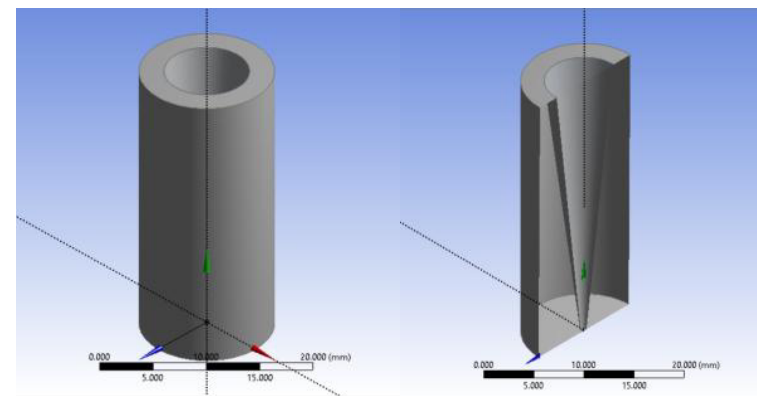

Figure 13. Isometric and section view of nozzle

Nozzle wear is a big issue while performing AJM. Internal surface of nozzle gets eroded due to the collision of particles with the surface. A new material or material with enhanced corrosion resistance property can be made with help of powder metallurgy process. With high corrosion resistance, operating time for nozzle would be more and thus machining time would be less.

\subsection{Assembly}

Highly compressed air at about 5 bar pressure is incorporated in FR unit. $8 \mathrm{~mm} \mathrm{PU}$ pipe is used for connecting compressor and FR unit and also is used for further connections. Further FR unit supplies the air to the distributor. The distributor is mounted on the vertical stand. Distributor provides two supplies, one to the abrasive feeder and second to the mixing chamber. Ball valves are used to supply carrier gas to the abrasive feeder and mixing chamber. One safety valve is also incorporated on the distributer. Abrasive feeder chamber and mixing chamber are connected with sockets and ball valve and are mounted on the stand in the vertical line. The opening of the mixing chamber is provided with the female thread for providing the connection with the nozzle. The nozzle with the male thread is connected with the mixing chamber.

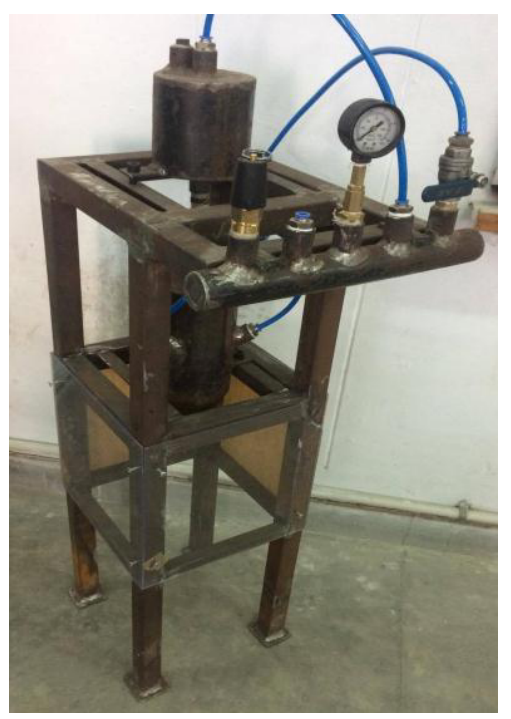

Figure 14. Assembly AJM

\section{Conclusion}

In this paper the design and fabrication of AJM is presented. The embedment of the abrasive particles was found to be the major reason of decrease in machining efficiency. In fabrication of AJM, abrasive feeder chamber and mixing chamber are incorporated in such a way that they receive the air separately through the air distribution system. This allows the restriction of abrasive particles from mixing in air when required. This air which does not contain the abrasive particles remove the embedded abrasive particles which will result into better machining efficiency.

\section{References}

1. R. Balasubramaniam, J. Krishnan, and N. Ramakrishnan, "Experimental study on the abrasive jet deburring of cross-drilled holes," J. Mater. Process. Technol., vol. 91, no. 1, pp. 178-182, (1999).

2. H. Wensink and M. C. Elwenspoek, "Reduction of 
sidewall inclination and blast lag of powder blasted channels," Sensors Actuators, A Phys., vol. 102, no. $1-2$, pp. 157-164, (2002).

3. T. Kuriyagawa and N. Yoshida, "T Kuriyagawa and Yoshida,” JSPE, vol. 54, no. 6, pp. 881-885, (1998).

4. D. S. Park, M. W. Cho, H. Lee, and W. S. Cho, "Micro-grooving of glass using micro-abrasive jet machining," J. Mater. Process. Technol., vol. 146, no. 2, pp. 234-240, (2004).

5. H. H.Getu, J. K. Spelt, and M. Papini, "Conditions leading to the embedding of angular and spherical particles during the solid particle erosion of polymers," Wear, vol. 292-293, pp. 159-168,(2012).

6 V. Hadavi, B. Michaelsen, and M. Papini, "Measurements and modeling of instantaneous particle orientation within abrasive air jets and implications for particle embedding," Wear, vol. 336-337, pp. 9-20, (2015).

7 L. Zhang, T. Kuriyagawa, Y. Yasutomi, and J. Zhao, "Investigation into micro abrasive intermittent jet machining," Int. J. Mach. Tools Manuf., vol. 45, no. 7-8, pp. 873-879, (2005).

8 Divyansh Mittal, Shankar Sehgal, and H. Kumar, "abrasive jet machining and its applications," Int. J. Sci. Res., vol. 2277, pp. 76-78, (2015).

9. "User manual for AutoCAD, 2016", publisher Autodesk, USA. 